\title{
AN INNOVATIVE APPROACH TO MANAGE UNCERTAINTIES AND STOCK DIVERSITY IN THE EPBD COST-OPTIMAL METHODOLOGY
}

\section{Damien GATT ${ }^{* 1}$, Charles YOUSIF ${ }^{2}$, Maurizio CELLURA ${ }^{3}$, Liberato CAMILLERI ${ }^{4}$}

${ }^{* 1,2}$ Institute for Sustainable Energy, University of Malta, Barrakki Street, Marsaxlokk, MXK 1531, Malta

${ }^{3}$ Università degli Studi di Palermo, Dipartimento di Energia, Ingegneria dell' Informazione e Modelli Matematici, Viale delle Scienze Edificio 9, 90128 Palermo, Italy

${ }^{4}$ Department of Statistics and Operations Research, University of Malta, Malta *damien.gatt@um.edu.mt

Received: 18 February 2018; Accepted: 27 April 2018

The EU Energy Performance of Buildings Directive (EPBD) 2010/31/EU is a step in the right direction to promote near zero energy buildings (NZEB) in a step-wise manner, starting with minimum energy performance and cost optimal thresholds for "reference buildings" (RBS) for each category. Nevertheless, a standard method for defining RBs does not exist, which led to a great divergence between MS in the level of detail used to define RBs for the EPBD cost-optimal analysis. Such lack of harmonisation between MS is further evident given the resulting large discrepancies in energy performance indicators even between countries having similar climate. Furthermore, discrepancies of $30 \%$ or higher between measured energy performance and that derived from the EPBD software induces uncertainty in the actual operational savings of measures leading to cost-optimality or NZEB in the simulated environment. This research proposes a robust and innovative framework to better handle uncertainties in the EPBD cost-optimal method both in the building software input parameters and in the global Life Cycle Costings (LCC), making the EPBD more useful for policy makers and ensuring a more harmonised approach among MS. The concept behind the proposed framework is the combination of a stochastic EPBD cost-optimal approach with Bayesian bottom-up calibrated stock-modelling. A new concept of "reference zoning" versus the "reference buildings" approach is also introduced in this research, which aims at providing a simpler and more flexible aggregation of energy performance for the more complex commercial building stock.

Key words: Stock modelling, EPBD cost-optimal method, Bayesian calibration, reference zones 


\section{Introduction and objectives}

The building sector is a substantial energy consumer accounting for around $40 \%$ of total primary energy consumption and 36\% of greenhouse gas (GHG) emissions in Europe [1] (at world level it accounts for around 32\% of the energy consumption [2]). The European Union (EU) has set ambitious targets to reduce the domestic GHG emissions by at least $80 \%$ by 2050 compared to 1990 levels [3]. Within this framework, the existing building stock has the highest potential for energy savings [4], thus calling for accelerated actions for deep building renovations [5]. The importance of such renovation is highlighted by the fact that the building turnover rate is low and the building stock only renews by about $1 \%$ per year in Europe [6] (1-2 \% per year [7]), and therefore existing buildings present the greatest opportunity for energy efficiency improvement. Buildings renovation can reduce $80 \%$ of that $40 \%$ total primary energy that is consumed by buildings in the EU, equivalent to $30 \%$ of the total EU primary energy consumption [8].

Given the need to improve the energy performance of the building sector, there has been a growing interest all over the world in building stock modelling that will allow the use of simulation tools to achieve an accurate analysis and dynamic prediction of the energy needs and performance of building stocks [9]. This is augmented by the fact that simulation models can predict and recreate visible phenomena that are not normally observable or hard to predict [10]. If these tools are properly executed and validated, they will become a great asset for policy makers in establishing appropriate energy performance benchmarks and in promoting suitable support measures to reduce energy consumption and $\mathrm{CO}_{2}$ emissions from the building sector. The strength in such tools lies in their ability to predict in a dynamic way the current and future energy consumption and $\mathrm{CO}_{2}$ emissions scenarios induced by different technologies, retrofit actions or policies [11].

As depicted in the Energy Performance of Buildings Directive Recast 2010/31/EU [1], the EU has understood the importance for MS to have a clear understanding of their building stock prior to establishing "cost-optimal" and "nearly zero" (NZEB) energy performance requirements for new and existing buildings undergoing major renovation. MS are consequently required to define "reference buildings" (RBs) that should represent "the typical and average building stock in a member state" [1]. Application and analysis of different combinations of measures to RBs using energy simulation tools is required by MS prior to establishing such energy performance benchmarks.

The correct choice of RBs is therefore crucial to allow MS to obtain general energy performance requirements consistent with the characteristics of their representative building stock. The cost optimal energy requirement is the "energy performance that leads to the lowest cost during the estimated economic lifecycle of the building" [1], while NZEB is a building that "has a very high energy performance with a low amount of energy required covered to a very significant extent by energy from renewable sources, including energy from renewable sources produced on-site or nearby"[1]. New and existing buildings undergoing major renovation require abiding by the cost optimal energy requirements, while NZEB requirements for public authority buildings will come in force by the end of 2018 and by 2020 for all other buildings.

Despite their crucial role, the identification of the correct choice of RBs for the different residential and non-residential building categories identified in the EPBD is not an easy task, given the large amount of geometric and non-geometric information required to correctly define them [11], which are often difficult to obtain. In addition, there is currently no standard methodology or harmonised 
process for defining RBs [12], [13]. This led to a significant divergence between MS in the level of detail used to define RBs for the EPBD cost-optimal analysis [12], [14].

Moreover, the minimum energy performance requirements for the different building categories are calculated via the national calculation methodology, which employs conventional building energy simulation software tools that are deterministic and do not consider inherent uncertainties in the building and its subsystems. Such tools also have limitations in their accuracy given that they are only an imitation of assumed processes defining energy transfer and consumption in a building. As a matter of fact, for non-domestic buildings in EU countries, discrepancies of up to 30\% [15], [16] or higher [17] between measured performance and energy performances derived from the EPBD compliant software have been reported.

Furthermore, a lack of harmonised approach to perform energy performance calculations among member states (MS) have also been shown. D'Agostino [18] identifies divergence in the different end uses and system boundaries considered by different MS for energy performance calculations, while Kurnitski et al. [19] report a large disagreement between energy performance indicators even between countries having a similar climate.

Inspired by the research of Booth et al. [20] and Sokol et al. [21], this paper proposes an innovative framework that ensures a more robust and harmonised approach to the EPBD cost-optimal method. This is achieved by the requirement for the (software) energy performance of RBs to be aggregated, stochastically (Bayesian) calibrated and validated with measured energy stock consumption data via an urban building bottom-up stock modelling approach. This will allow the EPBD to better handle and quantify uncertainties in outputs and to encompass building stocks diversity which allows the definition of comparable and more representative building energy performance benchmarks throughout the EU. In addition, this calibrated approach will enable policy makers to better identify (actual) operational energy savings induced by different policy measures for a particular building stock.

Furthermore, this research will also aim to counteract the difficulties of defining RBs for the less standard commercial building stock by the use of innovative 'reference zones' meta-models instead of the physical "reference buildings" currently applied in the EPBD recast [1]. Given that zones are situated at a lower hierarchal level than buildings in stock modelling, it is hypothesised that they allow a more flexible aggregation of energy performance data input at zone(s) level to any building typology and its further aggregation to regional or national level.

Section 2 provides the basic background to this research. Section 3 details the proposed method taking the non-residential hotel building stock as an example to help illustrate the method. Future research is intended to apply and analyse the proposed methodology in this research paper to the actual hotel building stock in Malta.

\section{Background}

\subsection{The EPBD cost-optimal method}

The EPBD recast [1] cost optimal calculation methodology is summarised below:

- Step 1: Define RBs for the various categories of buildings named in the directive;

- Step 2: Define and apply a set of packages of energy efficiency and energy supply measures to these RBs (COMs); 
- Step 3: Calculate the primary energy consumption (PEC) of the RBs for the various package of measures;

- Step 4 : Calculate the difference in life cycle costing ( $\mathrm{dLCC}$ per $\mathrm{m}^{2}$ of a building) for any package of measures, when compared to the RB as per EPBD recast [1] methodology;

- Step 5: Plot the results from the energy calculation (PEC) with the financial calculation (dLCC) as shown in Figure 1. The left part of the curve, starting from the cost-optimal point, represents the optimal solutions toward Nearly Zero Energy Buildings (NZEB), where the extreme left of the curve is the Zero Energy Building (ZEB) optimal solution.

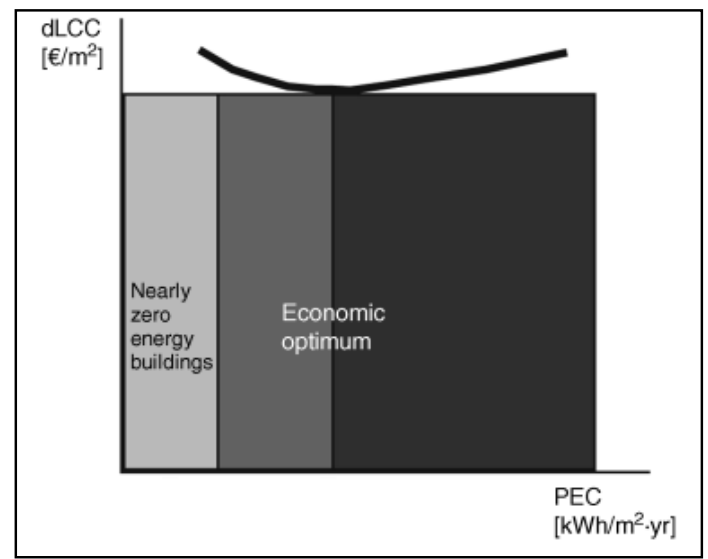

Figure 1: Plot showing the cost Optimum range (reproduced from [22])

\subsection{Defining Reference Buildings}

A standard methodology for defining RBs does not exist [14], [15], which makes the definition of RBs complex and subjective. A lack of harmonised process led to a substantial divergence between member states in the extent of detail when defining RBs as explained in [14], [16].

Given such lack of harmonisation, the EU projects (TABULA (2009 - 2012) [23], ASIEPI and EPISCOPE (2013-2016) [24]) have aimed to create a harmonised structure for "European building typologies" [9] for residential building stocks. This led to several research being published in the EU for residential building stock typologies including [25]-[40]. These EU projects have however only focused on the residential sector.

Despite the lack of standard methodology, Schaefer et al. [13] highlight that RBs in various studies have been obtained using a similar two step procedure as follows:

- Step 1: The building stock under study is well-defined, according to factors such as its functionality and climatic region;

- Step 2: Data is analysed to recognise the most recurrent and representative features of a stock, to set up one or more RBs for that stock.

Corgnati et al. [12], inspired by Department of Energy (DOE) RB models [41], defined the following four sub-sets of data that required to be collected for defining RBs in the EPBD as follows:

- $\quad$ Form

- Envelope

- $\quad$ System and

- Operation 
Furthermore, Ballarini et al. [9] categorises building topologies for the EPBD cost-optimal method according to three parameters:

- $\quad$ Location related to the climatic area;

- $\quad$ Construction period;

- $\quad$ Building size and shape.

RBs belonging to each location, construction period and form are characterised by the analysis and processing of building stock data via the application of one or a combination of the following three methodological approaches for the EPBD:

- "Example (Reference) Building" [12] or "RBv_exp methodology" [42] is used when no statistical data is available and relies on experts' assumptions and studies.

- "Real (Reference) Building" [12] also called "Real Average Building" (ReAv) [9] or "RBr methodology" [42] is the most typical existing building of a certain category, with average characteristics based on statistical analysis of a large building sample.

- "Theoretical (Reference) Building" [12], also called "Synthetical Average Building" (SyAv) [9] or "RBv_data methodology" [42] is a virtual building known as "archetype" [43] having "a statistical composite of the features found within a category of buildings in the stock" [43]. This method includes "the classification of the building stock into clusters of buildings" [44].

Archetypes are the most used practice in literature [44], as this is the most realistic method, which provides the best representative characteristics of the analysed samples. However, it depends on the availability of statistical data.

Another interesting approach depicted in literature but which is not included in the EU projects proposed methodologies for building stock analysis is "Brute Force" [44], which "includes the modelling and simulation of each single building of a building stock"1.

\subsection{RBs for the non-residential building stock}

The largest amount of published literature and knowledge on RBs and building stock modelling in the EU is on residential building [14], [44] given:

- That residential buildings makeup 75\% [14] of the EU building stock and are responsible for $63 \%$ [45] of the EU final building stock energy consumption;

- $\quad$ The difficulties to model the largely diverse non-domestic building stock having multiple activities and uses [14], [44], [46].

Given the difficulties to define RBs for the commercial (non-residential) building stock for the EPBD, various literature has aimed for a customised approach to model the non-residential building stock. For example, Gatt et. al. [47] proposed the concept of customised (cost-optimal) energy performance benchmarks for school buildings in Malta. More recently, Buso et al. [14] proposed a method to describe and model (non-residential) multi-functional buildings, based on the distinction between their typical and extra energy uses and applied the concept to an Italian reference hotel.

\footnotetext{
${ }^{1}$ The availability of Geographic Information System (GIS) and/or satellite imagery to estimate important geometric features of buildings coupled to dynamic software simulation/meta-models (refer to [70]), automated zoning techniques (refer to [71])), and Bayesian calibration applied to a building stock has however reduced the difficulties of using this approach. The innovat ive concept of "reference zoning" proposed in this paper coupled with meta-models can further enable easier computation of the "Brute Force" approach for the non-domestic building stock too.
} 


\subsection{EPBD cost-optimal method uncertainties}

The assignment of (single) deterministic values applied to building envelope, equipment and schedules for calculating the primary energy of RBs, coupled with the subjective judgement in defining RBs and the deterministic approach of assigning life cycle costs (LCC) input parameters ${ }^{2}$ lead to many uncertainties in the EPBD cost-optimal method, which include:

i. The validity of the resulting energy performance benchmarks based on the asset rating as derived from the chosen RBs.

ii. The extent to which the derived benchmarks are representative of the building stock under study.

iii. The actual "operational" vs. "simulated" energy savings achieved by retrofitting a specific category of buildings to the defined minimum energy performance and which measures are suitable for promotion and/or incentivising in practice.

iv. The actual financial feasibility quantification of different energy efficiency and renewable energy measures.

Quantification of uncertainty in iii. and iv. above is crucial to enable policy makers define any required incentives for the cost-optimal measures found from the EPBD cost-optimal studies, to make them cost effective.

The main limitation to handle and quantify the above uncertainties in the cost-optimal method results because the EPBD applies a deterministic approach to predict buildings energy performance, which does not specify the requirement for the energy performance of RBS to be aggregated, stochastically calibrated and validated with measured energy stock consumption data via a "bottom-up" building stock modelling approach, as described in Section 2.5.

Therefore, calibration with measured energy consumption data is essential to quantify uncertainty in the RB models and increase confidence in the predictions of the chosen RBs and in the resulting energy performance benchmarks. Such a calibrated stock modelling approach using RBs will enable policy makers to predict in a dynamic way the current and future energy consumption and $\mathrm{CO}_{2}$ emissions scenarios induced by different technologies, retrofit actions or policies for a whole region or nation and thus increase the usefulness of RBs within the EU.

\subsection{Building stock modelling approaches}

In literature, building stock modelling has generally been categorised into two main approaches, the "top-down" approach and the "bottom-up" approach.

"Top-down models" are data-driven models [44] that investigate energy consumption or $\mathrm{CO}_{2}$ emissions of a building sector via historical data collections to evaluate the macroeconomic relations between energy consumption and long term changes within the existing building sector under analysis [14], [48]. The main advantage of top-down techniques lies in their use of widely available aggregate data that simplify the analysis. Such modelling is generally faster and less costly, due to the reduced requirements for collecting detailed descriptive data on buildings [43]. These models however do not investigate individual building models, different technology options or energy end-uses.

\footnotetext{
${ }^{2}$ Uncertain inputs to the LCC, including the capital and maintenance cost of COMs, are assigned as single (deterministic) values instead of a probabilistic classification of values.
} 
In contrast, the "Bottom-up" modelling or "stock aggregation"[43] works at a disaggregated level. According to Swan and Urgasal [49], the bottom-up approach "encompasses all models, which use input data from a hierarchal level less than that of the sector as a whole"

By calculating the energy consumption of individual end-uses, individual buildings, or groups of buildings, these models can be useful for estimating how various individual energy efficiency measures affect the primary energy and $\mathrm{CO}_{2}$ emission reduction [50]. These models provide a way to detect the key areas of improvement and to identify the most cost-effective or cost optimal (combination of) options to achieve carbon reduction or primary energy reduction targets, based on the different available technologies and processes [51]. By working at a disaggregated level, such models allow the development of the energy use trends of a sector without the need of long-records of historical data [49]. The main drawback of this approach is the requirement to input more detailed building information input data which may be difficult and time consuming to gather.

Building stock engineering (physics based) models typically use the following procedure [11], [49], [52]:

- Step 1: Develop RBs for a building stock under study as described in section 2.2;

- Step 2: Predict the unit energy consumption ${ }^{3}$ for each representative building of a specific building stock category, by using a building energy simulation tool;

- Step 3: Obtain the total energy consumption of the building stock category by aggregating the predicted unit energy consumptions with proper weighting factors (e.g. the number of units or floor area) for each RB.

The EPBD allows for energy performance calculations methods for RBs to be quasi steady-state or dynamic in compliance with EN ISO 13790 [53]. Quasi stead-state methods require less inputs and are faster to operate than dynamic models, but cannot effectively model demand-based controls or track peak loads [54].

Full dynamic software simulations are commonly applied via a range of commercially available software that include EnergyPlus [55], ESP-r [56], and TRNSYS [57]. The most popular software simulation programs including EnergyPlus [55], ESP-r [56], and TRNSYS [57] make use of the multizone physical model approach [58], [59], in which a building under analysis is divided into zones and the properties defining the thermodynamic state of each building thermal zone is characterised by uniform state variables (temperature, pressure, concentration, etc.) [58], [59]. The multi-zone concept of EnergyPlus [55] forms the basis of the "reference zone" approach developed in this research.

\subsection{Tackling uncertainty in building stock modelling}

The limitations and uncertainty issues in bottom-up engineering stock models are described in detail by Booth et al. [60], Lim and Zhai [11] and Naber at al.[61]. Building engineering simulation models, even when applied at single buildings level, are complex as they rely on many input parameters that are highly uncertain. Thus, assumptions must be made to operate these models. The uncertainty

\footnotetext{
${ }^{3}$ The unit energy consumption is calculated via the use of suitable normalising factor of the gross energy consumption. The most common example of energy use intensity factor is the energy consumption per net floor area
} 
problem becomes more pronounced when studying a building stock, given that only a chosen and limited number of archetypes can be used to represent the entire wide actual building distributions [61].

To incorporate and handle uncertainties, many studies have made use of stochastic energy models for both individual buildings and for building stock models. Stochastic energy models combine (deterministic) building energy models with the Monte Carlo (MC) sampling method to perform stochastic analysis. In this approach, the input parameters for each defined archetype are assigned and sampled randomly from a range of probable (input) building parameter distributions. This contrasts the deterministic approach, where each parameter is assigned a single (deterministic) value. Stochastic energy models therefore allow uncertainty and sensitivity to be analysed via the variations and correlations between the input(s) and output(s).

In addition to the stochastic approach, calibration to tune the inputs in a model to match the observed data with the model outputs is essential to increase confidence in the predictions of a building stock model. Such calibration has proven difficult given that access to individual building data is rarely available [21].

The calibrated procedure can be performed either by a manual and time-consuming procedure or by an automated process that does not rely heavily on expert knowledge [62] i.e. using the probabilistic approach. In the probabilistic approach using Bayesian calibration, the unknown (uncertain) parameters to be calibrated are handled as random parameters with probability density functions [63] representing prior knowledge. Such distributions are known as "prior distributions", or simply "priors" [20].

To keep run times manageable for automated calibration, only dominant inputs having the highest impact on the model are calibrated. The choice of dominant inputs is found via a parameter screening method. Furthermore, to improve computational times, parameter screening is usually followed by the generation of a meta-model (surrogate model), which is a simplified algebraic or statistical model [21] replicating the more complex and detailed engineering based (building stock). This data-driven model is generated from samples of training data usually via stochastic model runs [64].

Kennedy and O'Hagan [65] proposed a generic approach for the Bayesian calibration of computer models. A Bayesian approach adjusts the "priors" based on evidence (measured data), as expressed by Bayes' theorem. The main outcome of the calibration process is the derived "posterior distributions" To create a full Bayesian probability model, these "posterior distributions" can be combined with a Monte-Carlo method. A validation procedure is finally required in which the calibration model output is compared with measured data. Bayesian calibration has only been applied recently on an urban or district scale to handle uncertainties in building stock modelling in studies which include [21], [52], [60], [66], [67] .

\section{Proposed EPBD cost-optimal approach}

To reduce the uncertainties in the current EPBD cost-optimal method, and to provide a more robust and harmonised approach among MS, an enhancement to the EPBD cost-optimal method is being proposed. This combines the current cost-optimal method discussed in section 2.1, the bottom-up stock modelling technique discussed in section 2.5 and the probabilistic Bayesian calibration approach discussed in section 2.6. In addition, to counteract the difficulties of handling building stock diversity for the commercial (non-residential) building stock as discussed in section 2.3, the concept of innovative 'reference zones' meta-models versus the physical "reference buildings" currently applied in the EPBD 
recast is being introduced. The proposed method ${ }^{4}$ illustrated in Figure 2 is demonstrated in the steps below by taking a hotel building stock under study as an example.

- $\quad$ Step 1: Cluster the hotel building stock

Classify i.e. cluster the hotel building stock under analysis into an optimal number of archetypes (RBs) according to different criteria based on literature review. Hotel building stock classification can be based on climatic zone, star rating, building age, hotel operating period, and number of bedrooms.

- Step 2: Define hotel reference zone/s for each building cluster

Divide each hotel building stock cluster into "reference zones" keeping the heat transfer between nearby zones and the exterior intact during simulation runs. Given that zones are situated at a lower hierarchal level than buildings in stock modelling, the hypothesis is that a simpler and more flexible aggregation of energy performance from zone level to building and even regional level is possible, while allowing faster computational times. Different zones defined for hotels can include bedrooms, halls, restaurants, kitchen and laundry.

- Step 3: Quantify uncertainty in model input parameters for each defined hotel "reference zone" in the form of probability density functions.

- Step 4: Perform Parameter screening for each defined "reference zone".

- Step 5: Design simulation experiments to generate a meta-model for each "reference zone". Use the Monte-Carlo (MC) sampling or the Latin hypercube sampling (LHS) method to stochastically simulate each defined "reference zone" using the dominant input parameters. Generate a unit energy consumption meta-model for each defined "reference zone".

- Step 6: Create an annual energy consumption meta-model for each hotel building stock cluster. Extrapolate the unit energy consumption meta-models for each reference zone to create a meta model for each hotel and for the entire hotel building stock cluster. The entire hotel building stock cluster is to be used for Bayesian calibration and is derived by the aggregation of "reference zone" meta models using proper weighing factors (such as floor area) for each zone.

- Step 7: Perform Bayesian calibration of the uncertain parameters for each building stock cluster. The Bayesian calibration is done using annual metered utility data of individual hotel buildings to obtain posterior distributions of the calibration parameters (from prior distributions).

- Step 8: Validate the Bayesian calibration using ASHRAE [68] normalized mean bias error (NMBE) and the coefficient of variance of the root mean square error [CV(RMSE)] criteria.

- Step 9: Define retrofit combination of measures to be applied to each hotel building stock cluster.

- Step 10: Define uncertainty surrounding LCC parameters using probability density functions.

- Step 11: Propagate uncertainty in the resulting primary energy performance and global costs outputs. Use the calibrated building stock cluster meta-model with the posterior parameter distributions to perform probabilistic sensitivity analysis using $\mathrm{MC}$ simulation to propagate uncertainty in the resulting primary energy performance and global costs output under the application of different combination of measures.

\footnotetext{
${ }^{4}$ EnergyPlus [55] is the software simulation of interest for this study. The programming languages R [72], JAGS [73] and Stan [74] can be used to perform the Bayesian analysis.
} 
- Step 12: Generate a Global cost $\left(€ / \mathrm{m}^{2}\right)$ vs Primary energy $\left(\mathrm{kWh} / \mathrm{m}^{2} /\right.$ year $)$ distribution plot. This distribution plot is generated for each hotel building stock cluster to analyse the resulting uncertainty in the cost-optimal energy performance for each building cluster.

- $\quad$ Step 13: Further analysis

Identify suitable policy measures and the calculation of potential energy savings from the hotel building stock under study.



Figure 2: Proposed EPBD cost-optimal approach (adopted from Heo [69]) 


\section{Conclusions}

This research paper has proposed an innovative framework to better handle uncertainties in the EPBD cost-optimal method both in the building software input parameters and for the global LCC. This is achieved by converting the deterministic EPBD cost-optimal method to a stochastic one and combining it with Bayesian calibrated bottom up stock-modelling. Such handling of uncertainties incorporated with the possible quantification in operational savings via the application of different combination of measures is intended to make the cost-optimal method more robust and useful for policy makers while ensuring a more harmonised approach among MS when specifying minimum energy performance requirements.

The new concept of "reference zoning" versus the "reference buildings" aims at providing a simpler and more flexible aggregation of energy performance from zone level to level for the less standard commercial building stock while also allowing faster computational times. Future research is intended to apply and analyse the proposed method to the actual hotel building stock in Malta.

The aim is to apply this method to both current and future climates to analyse the impact of climate change on the energy consumption of buildings. The "reference zone" approach can also be analysed further to verify the possibility of using this concept to provide customised energy performance benchmarks to the less standard commercial building stocks.

\section{References}

[1] Directive 2010/31/EU of the European Parliament and of the council of 19 May 2010 on the energy performance of buildings (recast), European parliament, 2010

[2] H. Khatib, IEA World Energy Outlook 2011-A comment, Energy Policy, 48 (2012), pp. 737-743

[3] Energy Roadmap 2050, European Union, 2012

[4] Y. Xing, N. Hewitt, P. Griffiths. Zero carbon buildings refurbishment-A Hierarchical pathway, Renewable ans Sustainable Energy Reviews, 15 (2011), 6, pp. 3229-3236

[5] T. Tsoutsos, S. Tournaki, C. A. de Santos, R. Vercellotti. Nearly Zero Energy Buildings Application in Mediterranean Hotels, Energy Procedia, 42 (2013), pp. 230-238

[6] P. Caputo, G. Pasetti, Overcoming the inertia of building energy retrofit at municipal level: The Italian challenge, Sustainable Cities and Society, 15 (2015), pp. 120-134

[7] D. Popescu, S. Bienert, C. Schützenhofer, R. Boazu, Impact of energy efficiency measures on the economic value of buildings, Applied Energy, 89 (2012), 1, pp. 454-463

[8] It Pays to Renovate, http://renovate-europe.eu/wpcontent/uploads/2015/09/RE_IT_PAYS_TO_RENOVATE_brochure_v05_spreads.pdf.

[9] I. Ballarini, S. P. Corgnati, V. Corrado, Use of reference buildings to assess the energy saving potentials of the residential building stock: The experience of TABULA project, Energy Policy, 68 (2014), pp. 273-284

[10] C. Tweed, Supporting argumentation practices in urban planning and design, Computer Environment \& Urban Systems, 22 (1998),4, pp. 351-363.

[11] H. Lim, Z. J. Zhai, Review on stochastic modeling methods for building stock energy prediction, Building Simulation, 10 (2017), 5, pp. 607-624

[12] S. P. Corgnati, E. Fabrizio, M. Filippi, V. Monetti, Reference buildings for cost optimal analysis: 
Method of definition and application, Applied Energy, 102 (2013), pp. 983-993

[13] A. Schaefer, E. Ghisi, Method for Obtaining Reference Buildings, Energy and Buildings, 128 (2016), pp. 660-672

[14] T. Buso, S. P. Corgnati, A customized modelling approach for multi-functional buildings Application to an Italian Reference Hotel, Applied Energy, 190 (2017), pp. 1302-1315

[15] L. Tronchin, K. Fabbri, A Round Robin Test for buildings energy performance in Italy, Energy and Buildings, 42 (2010), 10, pp. 1862-1877

[16] S. Petersen, C. A. Hviid, THE EEPD: Comparison of Calculated and Actual Energy Use in a Danish Office Building, Build. Simul. Optim. Conf., 2012, pp. 43-48

[17] E. Burman, D. Mumovic, J. Kimpian, Towards measurement and verification of energy performance under the framework of the European directive for energy performance of buildings, Energy, 77 (2014), pp. 153-163.

[18] D. D'Agostino, Assessment of the progress towards the establishment of definitions of Nearly Zero Energy Buildings (nZEBs) in European Member States, Journal of Building Engineering, 1(2015), pp. 20-32

[19] J. Kurnitski, T. Buso, S. P. Corgnati, A. Derjanecz, A. Litiu, nZEB definitions in Europe, REHVA European HVAC Journal, 51 (2014), 2, pp 6-9

[20] A. T. Booth, R. Choudhary, Decision making under uncertainty in the retrofit analysis of the UK housing stock: Implications for the Green Deal, Energy and Buildings, 64 (2013), pp. 292-308

[21] J. Sokol, C. Cerezo Davila, C. F. Reinhart, Validation of a Bayesian-based method for defining residential archetypes in urban building energy models, Energy and Buildings, 134 (2017), pp.1124

[22] S. Attia, H. Mohamed, S. Carlucci, P. Lorenzo, S. Bucking, A. Hasan: Building performance optimization of net zero-energy buildings in: Modeling, design, and optimization of net zero-energy buildings (ED. A. Athienitis, W. O'Brien), 2015, pp. 175-206.

[23] T. Loga et al., Use of building typologies for energy performance assessment of national building stocks existent experiences in European countries and common approach, TABULA project team, 2010

[24] EPISCOPE, Welcome to the joint EPISCOPE and TABULA, http://episcope.eu/index.php?id=97.

[25] E. G. Dascalaki, K. G. Droutsa, C. A. Balaras, S. Kontoyiannidis, Building typologies as a tool for assessing the energy performance of residential buildings - A case study for the Hellenic building stock, Energy and Buildings, 43 (2011), 12, pp. 3400-3409

[26] P. Florio, O. Teissier, Estimation of the energy performance certificate of a housing stock characterised via qualitative variables through a typology-based approach model: A fuel poverty evaluation tool, Energy and Buildings, 89 (2015), pp. 39-48

[27] J. Kragh, K. B. Wittchen, Development of two Danish building typologies for residential buildings, Energy and Buildings, 68 (2014), pp. 79-86

[28] N. Diefenbach et al., Application of Building Typologies for Modelling the Energy Balance of the Residential Building Stock, Institut Wohnen und Umwelt, Darmstadt, 2012

[29] T. Loga, B. Stein, N. Diefenbach, TABULA building typologies in 20 European countriesMaking energy-related features of residential building stocks comparable, Energy and Buildings 132 (2016), pp.4-12

[30] T. Csoknyai et al. Building stock characteristics and energy performance of residential buildings 
in Eastern-European countries, Energy and Buildings, 132 (2016), pp. 39-52

[31] C. A. Balaras, E. G. Dascalaki, K. G. Droutsa, S. Kontoyiannidis, Empirical assessment of calculated and actual heating energy use in Hellenic residential buildings, Applied Energy, 164 (2016), pp. 115-132

[32] D. K. Serghides, S. Dimitriou, M. C. Katafygiotou, Towards European targets by monitoring the energy profile of the Cyprus housing stock, Energy and Buildings, 132 (2016), pp. 130-140

[33] Magrini A., Magnani L., Pernetti R., Opaque building envelope, in: Building Refurbishment for Energy Performance (Ed. A. Magrini ), Green Energy and Technology, Springer, Cham, 2014, pp $1-59$

[34] D. D'Agostino et al., Synthesis Report on the National Plans for Nearly Zero Energy Buildings ( NZEBs ) Progress of Member States towards NZEBs, European Union, 2016

[35] P. Ferrante, G. Peri, G. Rizzo, G. Scaccianoce, V. Vaccaro, Old or new occupants of energy rehabilitated buildings, Two different approaches for hierarchizing group of buildings, Sustainable Cities and Society, 34 (2017), pp. 385-393

[36] C. Cerezo Davila, C. F. Reinhart, J. L. Bemis, Modeling Boston: A workflow for the efficient generation and maintenance of urban building energy models from existing geospatial datasets, Energy, 117 (2016), pp. 237-250

[37] I. Sartori, N. H. Sandberg, H. Brattebø, Dynamic building stock modelling: General algorithm and exemplification for Norway, Energy and Buildings, 132 (2016), pp. 13-25

[38] I. Ballarini, V. Corrado, A New Methodology for Assessing the Energy Consumption of Building Stocks, Energies, 10 (2017), no. 8:1102

[39] N. Tornay, R. Schoetter, M. Bonhomme, S. Faraut, V. Masson, GENIUS: A methodology to define a detailed description of buildings for urban climate and building energy consumption simulations, Urban Climate, 20 (2016), pp. 75-93

[40] D. K. Serghides, S. Dimitriou, M. C. Katafygiotou, M. Michaelidou, Energy efficient refurbishment towards nearly zero energy houses, for the mediterranean region, Energy Procedia 83 (2015), pp. 533-543

[41] P. Torcellini, M. Deru, B. Griffith, K. Benne, DOE Commercial Building Benchmark Models Preprint, ACEEE Summer Study Energy Efficiency in Buildings, 12 (2008)

[42] A. Brandão de Vasconcelos, M. D. Pinheiro, A. Manso, A. Cabaço, A Portuguese approach to define reference buildings for cost-optimal methodologies, Applied Energy, 140 (2015), pp. 316328

[43] S. Moffatt, Stock aggregation, Methods for Evaluating the Environmental Performance of Building Stocks, Annex 31 Energy-Related Environmental Impact of Buildings, Canada Mortgage and Housing Corporation, 2004

[44] G. Kazas, E. Fabrizio, M. Perino, Energy demand profile generation with detailed time resolution at an urban district scale: A reference building approach and case study, Applied Energy, 193 (2017), pp. 243-262

[45] G. V. Fracastoro, M. Serraino, A methodology for assessing the energy performance of large scale building stocks and possible applications, Energy and Buildings, 43 (2011), pp.844-852

[46] R. Choudhary, Energy analysis of the non-domestic building stock of Greater London, Building and Environment, 51 (2012), pp. 243-254

[47] D. Gatt, C. Yousif, Renovating Primary school buildings in Malta to achieve cost-optimal energy 
performance and comfort levels, SBE 16 Malta International Conference, Malta, 2016, pp. 453460

[48] T. Alves, L. Machado, R. G. de Souza, P. de Wilde, A methodology for estimating office building energy use baselines by means of land use legislation and reference buildings, Energy and Buildings, 143 (2017), pp. 100-113

[49] L. G. Swan, V. I. Ugursal, Modeling of end-use energy consumption in the residential sector: A review of modeling techniques, Renewable and Sustainable Energy Review, 13 (2009),8, pp. $1819-1835$

[50] M. Kavgic, A. Mavrogianni, D. Mumovic, A. Summerfield, Z. Stevanovic, M. Djurovic-Petrovic. A review of bottom-up building stock models for energy consumption in the residential sector, Building and Environment, 45 (2010),7, pp. 1683-1697

[51] Nic Rivers, Mark Jaccard, Combining Top-Down and Bottom-Up Approaches To EnergyEconomy Modeling Using Discrete Choice Methods, The Energy Journal, 26 (2005), pp. 83-106

[52] W. Tian, R. Choudhary, A probabilistic energy model for non-domestic building sectors applied to analysis of school buildings in greater London, Energy and Buildings, 54 (2012), pp. 1-11

[53] EN ISO 13790: 2008 Energy performance of buildings-Calculation of energy use for space heating and cooling, International Organization for Standardization, 2008

[54] CIBSE AM 11: 2015 Building performance modelling Building performance modelling. CIBSE, London, 2015

[55] The United States Department of Energy, EnergyPlus, https://energyplus.net/.

[56] University of Strathclyde, ESP-r, http://www.esru.strath.ac.uk/Programs/ESP-r.htm.

[57] F. Kentli, M. Yilmaz Mathematical modelling of two-axis photovoltaic system with improved efficiency. Elektronika Ir Elektrotechnika, 21(4), (2015), pp. 40-43.

[58] A. Foucquier, S. Robert, F. Suard, L. Stéphan, A. Jay, State of the art in building modelling and energy performances prediction: A review, Renewable Sustainable Energy Review, 23 (2013), pp. 272-288

[59] N. Fumo, A review on the basics of building energy estimation, Renewable Sustainable Energy Review, 31 (2014), pp.53-60

[60] A. T. Booth, R. Choudhary, D. J. Spiegelhalter, Handling uncertainty in housing stock models, Building and Environment, 48 (2012), pp. 35-47

[61] E. Naber, R. Volk, F. Schultmann, From the Building Level Energy Performance Assessment to the National Level: How are Uncertainties Handled in Building Stock Models, Procedia Engineering, 180 (2017), pp. 1443-1452

[62] M. Riddle, R. T. Muehleisen, A Guide to Bayesian Calibration of Building Energy Models, ASHRAE/IBPSA-USA Building Simulation Conference, Atlanta, 2014

[63] W. Tian, Q. Wang, J. Song, S. Wei, Calibrating Dynamic Building Energy Models using Regression Model and Bayesian Analysis in Building Retrofit Projects, IBPSA eSim 2014, 2014

[64] A. Mastrucci, P. Pérez-López, E. Benetto, U. Leopold, I. Blanc, Global sensitivity analysis as a support for the generation of simplified building stock energy models, Energy and Buildings, 149 (2017), pp. 368-383.

[65] M. C. Kennedy, A. O'Hagan, Bayesian calibration of computer models, Journal of the Royal Statistical Society, Statistical Methodology Series B, 63 (2001), 3, pp. 425-464 
[66] Y. Yamaguchi, R. Choudhary, A. Booth, Y. Suzuki, Y. Shimoda, Urban-scale energy modelling of food supermarket considering uncertainty, , Building Simulation (Ed. E.Wurtz), 13 ${ }^{\text {th }}$ International Conference of the International Building Performance Simulation Association France, 2013, Vol. 1, pp. 1326-1333

[67] F. Zhao, S. H. Lee, G. Augenbroe, Reconstructing building stock to replicate energy consumption data, Energy and Buildings, 117 (2016), pp. 301-312

[68] ANSI/ASHRAE, ASHRAE Guideline 14-2014 Measurement of Energy and Demand Savings, ASHRAE, 2014

[69] Y. Heo, Bayesian Calibration of Building Energy Models for Energy Retrofit Decision-Making under Uncertainty, Ph. D. thesis, Georgia Institute of Technology, USA, 2011

[70] C. F. Reinhart, C. Cerezo Davila, Urban building energy modeling - A review of a nascent field, Building and Environment, 97 (2016), pp. 196-202

[71] T. Dogan, C. Reinhart, P. Michalatos, Autozoner: an algorithm for automatic thermal zoning of buildings with unknown interior space definitions, Journal of Building Performance Simulation, 9 (2016), 2, pp. 176-189

[72] The R Project for Statistical Computing. The R Foundation. https://www.r-project.org/.

[73] JAGS. http://mcmc-jags. sourceforge.net/

[74] Stan. http://mc-stan.org/ 